\title{
Deleuze, Merleau-Ponty e os desafios da diferença
}

\author{
Silvana de Souza Ramos \\ ramos_si@yahoo.com.br \\ Universidade de São Paulo, São Paulo, Brasil
}

resumo Que significa fazer uma filosofia da diferença? Como é possivel captar o movimento singular de algo, sem subordiná-lo a categorias universais, sem submetê-lo aos limites da identidade e da representação? Ademais, como podemos capturar a experiência de nós mesmos sem reduzi-la à expressão de faculdades desde sempre prontas para agir sob a unidade sintética de um eu ou, ainda, sem espacializar a densidade criadora que a permeia? Certamente, essas questões ditam o norte do pensamento de Deleuze, embora já estivessem de algum modo presentes na filosofia de Merleau-Ponty, sugerindo direções pouco exploradas pelo autor de Diferença e Repetição. Afinal, enquanto Merleau-Ponty pretende desvelar o caráter originariamente não-intelectual das ligações produzidas no interior da experiência, Deleuze busca dar dignidade ontológica à diferença tomada em si mesma. Sendo assim, o objetivo deste artigo é fazer uma reflexão sobre o lugar concedido à diferença nos dois filósofos no intuito de compreender alguns dos desafios enfrentados por um pensamente que recusa submeter-se ao império da identidade.

palavras-chave Deleuze, Merleau-Ponty, identidade, diferença

Não há dúvida de que os escritos de Deleuze buscam colher na história das idéias os indícios de um pensamento da diferença - isto é, de um pensamento que se sabe criador, e que se porta como expressão capaz de tocar a mobilidade do real sem manipulá-lo. Um pensamento forçado pela desarmonia entre as faculdades e violentado pelo que simplesmente advém ${ }^{1}$. Esse projeto não teria qualquer sentido se não pudéssemos descobrir uma espécie superior de correspondência ou, melhor dizendo, 


\section{4}

de contato entre a interioridade e a exterioridade. É verdade que Deleuze explica o surgimento da diferença como aquilo que ultrapassa o dado bruto. Pois, como afirma, por exemplo, na monografia dedicada ao empirismo, foi Hume quem nos ensinou que não é o dado que produz a diferença. O Sol nasce repetidas vezes; porém, quando essa repetição se torna espera de um amanhecer futuro, há um novo que brota no espírito, e não na coisa. Entretanto, isso não nos deve fazer esquecer o esforço de Deleuze para mostrar que o próprio real nos interpela com suas novidades. Afinal, se a diferença não cintilasse nas dobras do ser - nas coisas mesmas -, se ela fosse apenas o desdobrar de um existir capaz de consciência, nada teríamos além de um novo capítulo do idealismo, liberto dos moldes da representação. Sabemos, todavia, que Deleuze era consciente de sua própria ambição ontológica. Pois, antes mesmo de alardear sobre o plano de imanência, em livro tardio escrito com Guattari² ${ }^{2}$ o filósofo pondera, num comentário à obra de Bergson:

Se há qualidade nas coisas, não menos que na consciência, se há um movimento de qualidades fora de mim, é preciso que as coisas durem à sua maneira. É preciso que a duração psicológica seja tão-somente um caso bem determinado, uma abertura a uma duração ontológica (DELEUZE, 1999, p. 37).

Evidentemente, o problema não diz respeito somente à filosofia de Bergson ou à de Hume, uma vez que acentua uma articulação importante e decisiva no interior da filosofia da diferença: afinal, não basta experimentar a diferença, ou permitir-se o abandono à duração interna; é preciso encontrá-la ali onde o pensamento identificador a escamoteia; é preciso enxergar no real a produtividade imanente que a ontologia tradicional foi incapaz de perceber e de qualificar. Falamos de um pensamento movente que anseia tocar o real, sem manipulá-lo. Por isso, intervém aqui uma preciosa distinção bergsoniana - central na descrição da evolução criadora e que fará fortuna sob a pena de Deleuze: a diferença entre intuição e inteligência, na medida em que a primeira, ao contrário da segunda, reivindica, para ser compreendida e experimentada, uma relação íntima do espírito consigo mesmo e deste com o real.

Ora, diz Bergson, há uma dificuldade inerente ao modo humano de inserir-se na duração. Analisemos essa dificuldade com o devido cuidado. 
Por um lado, é inegável que o advento da inteligência traz ao espetáculo da evolução um personagem crucial e único. $O$ ser inteligente não é simplesmente mais uma espécie que viria se somar às demais. A interpretação bergsoniana da evolução das espécies insiste ser desnecessário temer as descobertas de Darwin imaginando que circunscrevem uma nova ferida narcísica, ou seja, não se trata de compreendê-las como uma destituição dos privilégios e das peculiaridades que fazem do homem algo de diverso e de inédito no seio da natureza. Afinal, nunca havia surgido sobre a Terra um ser capaz de se adaptar com tamanha eficácia e destreza, capaz de expandir seus domínios, para além do mero interesse imediato de sobrevivência. Bergson nos ensina que o ser inteligente marca uma ruptura em relação às demais espécies, assinalando uma nova maneira de ser vivente. Ora, é preciso salientar que tal ruptura não desliga o homem da produtividade característica do elã vital, pelo contrário: o ser vivo inteligente é um dos ramos da evolução. Porém, seu modo peculiar de dirigir-se no meio em que vive torna-o cego em relação a si mesmo e à natureza que o circunda.

Por isso, é preciso dar conta da ruptura responsável por produzir o ser inteligente, compreendendo-a sob a poeira teórica legada pela tradição. É aqui que a dificuldade aparece com maior nitidez. Trata-se essencialmente de despertar para o fato de que o ser vivo inteligente não se define pela sapiência ou, ainda, por sua potência teórica ou contemplativa. O que nos faz homens é nosso poder fabricador, isto é, nossa afinidade simultânea com a matéria e com o possível, nosso desejo sempre renovado de ir além do domínio imediato de certos objetos mediante a fabricação incessante de instrumentos, incluindo-se aí a própria linguagem. Dito de outro modo, o que nos coloca por assim dizer no ápice da criação é uma inteligência instrumental e prática ${ }^{3}$.

Seria incorreto defender que Bergson se incomoda com essa descoberta ou que seu objetivo seja o de simplesmente desqualificar a inteligência: basta percorrer com cuidado as páginas da Evolução Criadora para perceber que há ali mais elogio do que repulsa ao nosso poder de fabricar. Contudo, não devemos esquecer que compreender o caráter ativo da inteligência significa conferir-lhe seu verdadeiro papel, para além das ilusões teóricas que constantemente engendra: toda a nossa ciência e o conseqüente domínio que alcançamos sobre a matéria - e mesmo a 


\section{6}

sociabilidade que nos liga através da linguagem - devem ser reputados à atenção prática propiciada pela inteligência. $O$ problema enfrentado por Bergson não reside, portanto, nas virtudes da inteligência. Ele aparece quando esta pretende teorizar: é aqui que topamos com um limite que precisa ser esclarecido e superado.

Pois, se o homem rompe com o modo instintivo de ser vivente, isso não significa que o protagonista dessa ruptura esteja disposto a se reconhecer como um simples fabricador. Pelo contrário, a história da metafísica está aí para atestá-lo: fruto de uma inteligência que desconhece sua verdadeira função, a metafísica só consegue produzir ilusões teóricas na medida em que se vale das prerrogativas da ação no intuito de abarcar algo que exigiria outro tipo de atenção. Obcecada em manipular e encorajada pelos resultados obtidos, a inteligência sente-se capaz de conhecer ou de teorizar, sem enxergar aí uma incompatibilidade flagrante. Pois, para conhecer, é preciso acompanhar os contornos do real sem recortá-lo, isto é, sem reduzi-lo a um conjunto de objetos inertes, justapostos num tempo espacializado, e oferecidos à ação humana. Noutros termos, para teorizar é preciso religar o homem ao todo da evolução, quer dizer, reintroduzi-lo numa certa continuidade em relação ao caráter explosivo e criativo do elã vital. Isso significa que para abarcar a duração inerente à vida e da qual o homem é tão somente um ramo, faz-se necessário violentar a inteligência, retirando-a dessa espécie de hipnose que a impede de contemplar a continuidade diferenciante que a enlaça aos ditames gerais da vida. Mas como fazê-lo?

Decerto, a Evolução Criadora tem um caráter depurativo, no sentido de nos obrigar a desvincular inteligência e teoria. Porém, não basta dizer que a função da inteligência é agir e não contemplar. A estratégia bergsoniana consiste em colocar a inteligência perante um "objeto" que resiste ao recorte e à descontinuidade. Este "objeto" - a vida e seu caráter evolutivo - foi descoberto no âmbito das investigações científicas, quando Darwin teve um momento de intuição. Contudo, basta descrever as trapalhadas científicas que insistem em vestir esse "objeto" com roupas inadequadas para notar a exigência de uma nova postura.

A ciência tenta explicar fenômenos patentes da evolução. Por exemplo, como dar conta ao mesmo tempo da complicação orgânica e da simplicidade funcional dos órgãos dos sentidos? Como descrever as 
mudanças sucessivas que produziram o olho e a visão em diferentes linhas evolutivas? Em vão o mecanicismo tenta circunscrever a formação da visão por adições sucessivas. Pois, sendo um órgão complexo e total, o olho não poderia aceitar uma alteração parcial sem colocar em risco a própria visão. Ademais, as adições tampouco poderiam dar conta de eixos de evolução aparentemente independentes. O finalismo, por sua vez, procura ver no surgimento do olho a realização de um plano previamente estabelecido. Isso permitiria compreender como as mudanças das diversas partes que compõem o olho poderiam caminhar numa única direção, tendo como objetivo sua realização eficiente nas diferentes espécies. Solução mais engenhosa. Entretanto, ela negligencia o fato de que a visão é um resultado criativo da evolução. Não estava, portanto, prevista ou pré-formada no intelecto divino ou em qualquer lugar. A visão é algo novo, e não basta determiná-la pela finalidade para dar conta do momento mesmo em que surge e das variações imprevisíveis que sofre no interior das diversas espécies. Por essas e por outras, o espetáculo da falência inteligente para compreender a vida em seu caráter criativo permite trazer à cena a intuição como seu contraponto eficaz.

Ora, a intuição não é a produção de meios para atingir fins indeterminados. Não é a produção de instrumentos indefinidamente desdobráveis. Ela é um método de dissolução de falsos problemas. Assim, sua primeira missão é fazer com que a inteligência reconheça seu limite, isto é, sua incompetência teórica. Cumpre-lhe mostrar que a inteligência é uma das linhas da evolução e não sua síntese. Afinal, para se estabelecer, o homo faber teve de abrir mão de outros caminhos; principalmente, teve de abandonar o instinto, quer dizer, teve de desprender sua atenção do movimento da duração inerente à própria vida. Mais precisamente, é preciso reconhecer que as espécies, os diferentes troncos e ramos da evolução, atualizam o elã vital. Sendo assim, se há uma verdade no finalismo, esta reside no fato de que a evolução responde de certo modo a uma unidade de movimento.

Mas essa unidade não está posta num fim último, perseguido por cada uma das espécies até a chegada do homem. Trata-se, ao contrário, de uma unidade de impulso. Todavia, o que se segue desse impulso é uma diferenciação incessante, de modo que é preciso reconhecer que, ao lado do ser inteligente, outras linhas evolutivas reverberam a força do elã vital. Por 


\section{8}

isso, nenhuma espécie sozinha pode realizá-lo inteiramente, embora cada uma carregue em torno de si - como uma vaga nebulosa - as potências que abandonou em função de sua diferença intrínseca. Não fosse assim, o projeto de uma racionalidade intuitiva capaz de violentar as amarras da inteligência seria inútil. Pois, se o homem não pudesse ver para além dos limites do interesse prático, não poderia contemplar o todo da evolução, isto é, não poderia enxergar para além de si mesmo. Em suma, não poderia se ver como uma diferença no interior da unidade de impulso que o abarca. Isso significa que a intuição implica uma atenção voltada para o todo da evolução, de maneira que seja possível inscrever aí a própria inteligência, sem fazer dela o lugar a partir do qual poderíamos descrever as diferentes explosões do elã vital.

Sabe-se que tais formulações trazem muitas conseqüências. Elas exigem que se faça uma gênese da própria inteligência no interior do processo evolutivo. Noutros termos, elas asseveram ser preciso escapar da ilusão kantiana segundo a qual não há nada para conhecer aquém do formalismo cômodo do entendimento. Então, não podemos ter uma relação absoluta com o real? Não é possível acompanhar a duração sem enlouquecer? Sim, desde que se faça uma verdadeira crítica do entendimento. É preciso mostrar que a inteligência não conhece, que ela simplesmente recorta e mortifica uma realidade que em si mesma é vida e duração. A inteligência tem afinidade com a distensão da matéria, e só poderia falsificar a realidade do movimento vital, não podendo dar conta da evolução criadora. De qualquer modo, isso significa que há uma objetividade própria à filosofia, há algo que escapa ao formalismo interessado do entendimento e que é preciso conhecer. É por isso que uma nova teoria do conhecimento se esboça no interior da filosofia de Bergson, como se pode depreender de uma passagem do início da Evolução Criadora:

Uma teoria da vida que não vem acompanhada de uma crítica do conhecimento é forçada a aceitar, tais e quais, os conceitos que o entendimento põe à sua disposição: não pode fazer mais que encerrar os fatos, por bem ou por mal, em quadros preexistentes que ela considera como definitivos. Obtém assim um simbolismo cômodo, talvez mesmo necessário à ciência positiva, mas não uma visão direta de seu objeto. Por outro lado, uma teoria do conhecimento que não reinsere a inteligência na evolução geral da vida não nos ensinará nem 
como os quadros do conhecimento se constituíram, nem como podemos ampliá-los e ultrapassá-los. É preciso que essas duas investigações, teoria do conhecimento e teoria da vida, se encontrem e, por um processo circular, se impulsionem uma à outra indefinidamente (BERGSON, 2005, p. XIIIXIV, grifo nosso).

A passagem concentra o propósito do livro em diversos aspectos, e lança luz sobre o projeto teórico de Deleuze. A inteligência é sim um ramo da evolução - ela é, como dissemos, um modo de ser vivente. Nestes termos, ela atualiza algo da virtualidade do elã vital ao desprender-se do instinto. Porém, torna-se obscura para si mesma quando não é forçada a alargar-se em direção ao todo da evolução, a tentar recolher os ramos que deixou para trás. Forçar a inteligência a reconhecer-se significa impulsioná-la a uma violência contra si mesma. Por isso, a intuição como método põe em xeque o formalismo cômodo do entendimento. Acostumado a formalizar e a distender o real, o entendimento terá de reconhecer que não consegue verdadeiramente tocá-lo, ainda que o manipule sem cessar. Em suma, a teoria da vida vê-se acompanhada por uma teoria do conhecimento na medida em que faz a gênese da inteligência sem se limitar ao formalismo que a última tenta lhe impor; abrindo-se, portanto, a uma relação diversa com o real.

Mas como o método intuitivo contempla a evolução criadora? Em primeiro lugar, ele se desfaz das roupas do entendimento. Não fíca oscilando sem cessar entre o mecanismo e o finalismo. Deve afastar-se desses modos de compreender a vida, considerando que esta é indiscernível de um tempo qualificado, isto é, de um tempo não-homogêneo e, por isso mesmo, criador. É preciso compreender verdadeiramente o que significa durar, diferenciando-o do mero suceder. Se a evolução se movimentasse aos pulos, se uma duração não a atravessasse, não poderíamos explicar as convergências e as divergências qualitativas que caracterizam a história da vida. Por exemplo, não daríamos conta da mobilidade que rastreia a planta, da inteligência que por vezes se destaca no animal, do instinto que percorre o sonâmbulo. São figuras diversas de um mesmo fundo evolutivo as quais reiteram com certa independência a unidade do elã vital, diversificando-o. São tendências que guardam o contrário no interior de si mesmas. O que faz o tempo espacializado 
preconizado pela inteligência? $\mathrm{Na}$ medida em que formaliza a evolução, ele tende a dividi-la em momentos sem abarcar os intervalos, ou seja, sem atentar para a duração da própria tendência e sem considerar as forças contra as quais ela luta.

Assim, se há uma unidade de impulso que percorre toda a evolução da vida dando-lhe sentido, é preciso considerar que este algo não é um possível. O possível é um primo nobre - porque metafisico - do tempo espacializado da ciência. Ele pretende dar dignidade ontológica à existência usurpando-lhe o essencial, ou seja, sua potência criadora. Que significa reduzir o ser da existência a um possível? Significa considerar que há uma identidade entre a potência e o ato, ou seja, entre aquilo que é em idéia e aquilo que vem à existência, entre o projeto e a obra. O possível não pode, portanto, admitir a criação porque esta já estaria prevista no plano evolutivo. De pronto, o possível nos afasta da evolução criadora. Mas de onde vem essa idéia de que o existente é precedido por um ser possível, embora ainda não realizado? Do costume da inteligência de arquitetar planos com vistas a resultados práticos. A inteligência faz constantemente este caminho: ela nunca é agora, sempre pensa adiante, sempre guarda uma potência ainda não realizada, vagando em abstrações que preparam sua prática. Porém, diz Bergson, o elã vital não é um conjunto de formas que simplesmente se repetem na existência. Ele é todo virtual. E o virtual se atualiza na duração, quer dizer, evolui criativamente.

Deleuze se aproveita da engenhosa teoria da diferença que aqui se esboça. Ele explora o fato de que o virtual não é, como o possível, algo que se degrada ou que se repete no tempo e no espaço. Ser virtual significa atualizar-se por diferenciação. Essa diferenciação não anula o conflito, pelo contrário, dele se alimenta. Afinal, os troncos da evolução são antagônicos na medida em que expressam tendências opostas do elã vital, acentuando as divergências: conservação e explosão de energia, movimento e fixidez, atenção à qualidade e formalização etc. Dito de outro modo, a evolução é o espetáculo de uma unidade que abarca desarmonias. Por tudo isso, é preciso compreender que a passagem do virtual ao atual multiplica qualitativamente o elã vital. Há aqui a passagem do simples ao complexo, já que a vida procede por dissociação e desdobramento. Segundo o linguajar deleuziano, a totalidade virtual é uma unidade simples que se atualiza segundo linhas diver- 
gentes que se desenvolvem multiplicando criativamente aquilo que estava envolvido no elã vital ${ }^{4}$.

Isso significa que precisamos considerar uma oposição ainda mais fundamental que todas aquelas contempladas pelo método intuitivo. Trata-se de verificar a oposição entre o virtual e sua própria atualização. Pois, para se atualizar, o elã tem de criar linhas positivas que o desdobrem criativamente. Chegamos ao ponto central da crítica à idéia de possível: o virtual não é, como o possível, um duplo estéril da evolução. É a inteligência que projeta no início os resultados ou os produtos da evolução. O método intuitivo, ao contrário, vai do composto, ou seja, dos resultados, à simplicidade virtual do elã. Ele atenta para o fato de que o simples não se divide, mas se diferencia em linhas divergentes. Assim, a intuição encontra no elã vital um princípio distraído que se atualiza sem respeitar planos ou perseguir metas e interesses práticos ${ }^{5}$.

Note-se que o pensamento de Deleuze se alimenta desse jogo entre as tendências divergentes que insistem em sua diferença e por isso são forçadas ao limite. De um lado, o saber de si - aquele que nos leva à criação e à liberdade - só pode ser incitado pela experiência do limite: limite do sensível que nos incita a pensar; limite de nossas faculdades que divergem e incitam umas às outras. Deleuze chama esse processo de "síntese disjuntiva", quando dois elementos são afirmados por suas próprias diferenças. De outro lado, o todo ou a duração real exige ir ao encontro das singularidades para alcançar uma realidade que é em si mesma devir e, por isso, ultrapassa criativamente seus próprios limites. É apenas considerando esses dois lados que podemos chegar à correspondência superior entre interioridade e exterioridade de que falávamos no início. Não se trata de reativar os vestígios de um pensamento da identidade, mas sim de repor criativamente na sensibilidade e no pensamento o jogo de diferenças que vigora no real.

Mas será que essa concepção não guarda nenhuma dificuldade? Dizer que o próprio jogo das diferenças ou, por outra, que a própria repetição incita o pensar ou, ainda, que o limite da inteligência dá lugar ao exercício da intuição não é assumir uma posição demasiadamente otimista? Aceitemos as lições de Bergson: todo pensamento começa com algo, o nada ou o formalismo cômodo é apenas uma ilusão retrospectiva incitada pela inteligência; sendo assim, o mesmo é a tentativa de domesticar o 


\section{2}

real, na medida em que este abarca duração. Dito isto, temos de considerar criticamente dois casos: 1) o momento em que a diversidade do real não é apreendida porque não criamos ainda um pensamento capaz de tocá-la; 2) o momento em que a realidade se repete e o pensamento espera que ali se produza algo mais do que a mera repetição. $O$ primeiro caso nos mostra que nem sempre as singularidades nômades nos obrigam a trilhar um caminho diverso de pensamento. No segundo caso, o pensamento força um limite ilusório. Mas de onde surgiriam tais descompassos? Eles não seriam sinais de fraqueza da própria teoria? Por certo, Bergson nos aconselharia o método da intuição para sanar possíveis danos, e Deleuze assinaria embaixo. Afinal, pelo que vimos, tal método aparenta ser eficaz perante os desafios de se pensar uma realidade movente e de certo modo imprevisível.

Ora, há uma peculiaridade na apreensão deleuziana do bergsonismo: sua vinculação a um empirismo superior. Trata-se de compreender que o real é duração que engendra singularidades e que estas jamais podem ser abarcadas por uma identidade que as aprisione. Isso porque, qualquer movimento do real, mesmo a repetição, produz diferença, e esta será sempre nômade, será sempre capaz de se afirmar na sua diferença e somente uma ilusão do entendimento poderá nos desprender dessa realidade. Reside aí a força do apelo a Hume: mesmo a expectativa que me faz crer que o Sol nascerá amanhã não é mera reiteração do mesmo, e sim diferença. Para dizer em poucas palavras: para pensar não é preciso identificar, pelo contrário.

É daí que Deleuze encontra forças para confiar na legitimidade de sua defesa da filosofia da diferença, pois qualquer processo de generalização poderia macular a pureza nômade das singularidades mergulhadas na multiplicidade do real. Desde então, qualquer tentativa de generalização apareceria como autoritarismo ou como redução da realidade movente a formalizações que a deturpam.

Sabe-se que Merleau-Ponty, diferentemente de Deleuze, nunca concedeu esse poder ou esse lugar privilegiado ao empirismo frente ao idealismo. Pelo contrário, a Fenomenologia da percepção é elaborada mediante a crítica tanto ao empirismo quanto ao intelectualismo, na medida em que ambos despojam o sensível da significação que lhe é própria. O intelectualismo, porque credita o sentido do mundo a uma doação da 
consciência; o empirismo, porque vê nos processos de associação de idéias a conjunção exterior de impressões atomizadas. Trata-se do primeiro passo do livro na elaboração do trajeto crítico aos prejuízos clássicos, o qual culmina com a defesa de uma expressividade imanente ao sensível e explorada pelo corpo próprio no interior da temporalidade da percepção ${ }^{6}$.

Sendo assim, o pêndulo empirismo-intelectualismo acompanha todo o livro, segundo o movimento da dialética merleau-pontiana, a qual tem por finalidade encontrar irmandades profundas entre pensamentos aparentemente rivais. Pois, nas diversas dimensões da experiência - na sexualidade, na percepção, na linguagem - tanto um quanto outro reitera os mesmos procedimentos responsáveis por escamotear o sentido da experiência vivida. De um lado, o intelectualismo faz do entendimento o centro produtor do sentido. Seguindo essa toada, ele teria de admitir, por exemplo, que nosso corpo não poderia alcançar a cadeira que lhe está próxima, sem que houvesse um cálculo intelectual da distância a ser percorrida e dos movimentos necessários para a execução do intento. Porém, a experiência concreta deixa claro que há um saber do corpo anterior à reflexão, capaz de realizar a tarefa sem necessitar da mediação do entendimento. De outro lado, o empirismo insiste em defender que o sentido de nossas impressões se produz na medida em que associações vão sendo fixadas pela repetição na experiência - embora tais associações não estejam no sensível. Como diz Deleuze, a ligação - a diferença - não surge na coisa, mas no espírito alimentado pela força do hábito.

Entretanto, o que está em jogo para Merleau-Ponty não é assegurar a singularidade nômade da diferença, libertando-a de toda e qualquer mediação, mas defender a originalidade da ordenação corporal da experiência, operante desde a percepção mais elementar. Por isso, qualquer filosofia que desconheça a ligação interna entre os sentidos e os gestos corporais, e entre as diferentes impressões provenientes do mundo, é julgada incapaz de compreender a riqueza concreta da experiência ${ }^{7}$. Podemos dizer então que Merleau-Ponty pretende desvelar o caráter originariamente não-intelectual das ligações em todos os níveis da experiência, ao passo que Deleuze busca dar dignidade ontológica às singularidades - isto é, à diferença tomada em si mesma ou em sua afirmação frente às demais. 
Isso significa que não podemos encontrar em Merleau-Ponty uma filosofia da diferença? Ora, fazer a redução fenomenológica implica encontrar uma sensibilidade portadora de seu próprio sentido, onde as ligações se processam internamente, e não dependem, portanto, das operações do entendimento. Assim, um pensamento da diferença, como o de Merleau-Ponty, assume que não há singularidade nômade, uma vez que não se pode, por exemplo, destruir na sensibilidade a ligação entre figura e fundo, a mais originária de todas. Portanto, para compreender a sensibilidade e o pensamento - e a potência de produzir o novo, ou, ainda, o poder da repetição e do hábito -, não basta garantir a pureza do diferente, já que é preciso compreender como a própria experiência se ordena em sistemas expressivos abertos.

Daí a necessidade de pensar generalidades que suportem um verdadeiro jogo de diferenças, desafio que Merleau-Ponty enfrentará a partir dos anos 1950, especialmente nas investigações sobre os sistemas diacríticos operantes na linguagem e na sensibilidade. Então, o filósofo buscará dar uma nova significação à idéia de sistema, sem ter de realizar um retorno à filosofia da representação, isto é, sem regredir a um pensamento identificador. Com isso, indica uma solução para as dificuldades surgidas posteriormente no pensamento de Deleuze: afinal o que fazer quando o pensamento deixa de tocar o real? Tratar-se-ia de mudar o foco: ao invés de insistir na irredutibilidade da diferença, dever-se-ia compreendê-la dentro do sistema onde ela se afirma. Essa atitude estaria em pleno acordo com o modelo bergsoniano da intuição, cioso em afirmar a importância da atenção voltada à totalidade, no interior da qual a noção de diferença pode verdadeiramente ganhar algum sentido.

\footnotetext{
${ }^{1}$ Neste ponto, é necessário fazer uma pequena observação de ordem metodológica, na medida em que o modo de compreender o exercício do pensamento engendra uma atitude em relação aos textos do passado. Afinal, como é possível encontrar no pensamento moderno, marcado pela filosofia da representação, elementos capazes de impulsionar uma filosofia da diferença? Isso se torna viável na medida em que, para Deleuze, um texto é "algo que ultrapassa a si mesmo, que não tem uma identidade a ser apreendida, mas uma intensidade a ser vivida por alguém que se põe em relação com ela, uma intensidade que não é a mesma para todos os leitores, mas uma que é própria a cada um. Trata-se de uma recusa de toda mediação, tanto da parte de um instrumental metodológico que identifica o leitor como apto a dar
} 
conta do texto, quanto da estrutura de um determinado sistema conceitual auto-referente. Antes, o texto é tratado como um jogo de forças em contato com as forças do exterior, que tanto arranca-as de seus limites como atravessa-as, dando-lhes, a cada vez, um movimento novo, um arranjo de sentidos sempre renovado em virtude desse contato" (FORNAZARI, 2005, p. 16).

2 Trata-se de O que é filosofia?, publicado em 1991. Bergsonismo é de 1966.

3 Podemos notar com clareza o modo de proceder da inteligência descrito por Bergson em A Evolução Criadora: "uma inteligência que visa fabricar é uma inteligência que não se detém nunca na forma atual das coisas, que não a considera como definitiva, que toma toda matéria, pelo contrário, por talhável à vontade. (...) Exige que consideremos toda forma atual das coisas, mesmo das naturais, como artificial e provisória, exige que nosso pensamento apague do objeto percebido, mesmo organizado e vivo, as linhas que assinalam por fora sua estrutura interna, exige, enfim, que tomemos sua matéria por indiferente à sua forma. O conjunto da matéria deverá então aparecer para nosso pensamento como um imenso tecido no qual podemos talhar o que quisermos, para recosturá-lo como quisermos. Notemos de passagem: é esse poder que afirmamos quando dizemos que há um espaço, isto é, um meio homogêneo e vazio, infinito e infinitamente divisível, que se presta indefinidamente a todo e qualquer tipo de decomposição. Um meio desse tipo não é nunca percebido; é apenas concebido" (BER GSON, 2005, pp. 169-170, grifo nosso). Bergson destaca, portanto, o caráter formalizador da inteligência, na medida em sua função primordial é a de preparar o terreno para a ação humana, e não a de perceber o real em sua presença efetiva e singular.

${ }^{4}$ Por isso, Bergson insiste em salientar a fecundidade criativa do elã vital se comparada às produções da inteligência: "grandes direções surgirão, nas quais a vida se move desenvolvendo a impulsão original. Não se assistirá, é verdade, à execução detalhada de um plano. Há mais e melhor aqui do que um plano que se realiza. Um plano é um termo conferido a um trabalho: fecha o porvir do qual desenha a forma. Frente à evolução da vida, pelo contrário, as portas do porvir permanecem abertas de par em par. É uma criação sem fim, em virtude de um movimento inicial. Esse movimento faz a unidade do mundo organizado, unidade fecunda, de uma riqueza infinita, superior àquilo que qualquer inteligência poderia sonhar, uma vez que a inteligência é apenas um de seus aspectos ou produtos” (BER GSON, 2005, p. 114).

5 Daí o papel da ação das intensidades na filosofia de Deleuze, pois, como explica Fornazari: "O virtual é inseparável de um processo de atualização das multiplicidades que o povoam. Cada multiplicidade se constitui pela coexistência virtual de relações diferenciais que se atualizam no extenso e nas qualidades empíricas. As relações diferenciais atualizam-se segundo a linha divergente que lhe é própria, encarnando-se em diferenças qualitativas ou extensivas. A diferenciação qualitativa e extensiva atual é correspondente e simultânea a uma diferenciação nas relações diferenciais da multiplicidade virtual. Mas o que é que determina as relações diferenciais a seguirem suas linhas divergentes diferenciando-se? O que leva a multiplicidade virtual a atualizar-se, encarnando-se em qualidades e em extensos diferenciados? São as quantidades intensivas que o fazem. A intensidade, em sua ação de explicação, que cria as qualidades e os extensos nos quais se desdobra, determina o movimento de atualização da multiplicidade virtual que se diferencia segundo suas linhas divergentes" (FORNAZARI, 2005, pp. 178-179).

doispontos, Curitiba, São Carlos, vol. 8, n. 2, p.83-97, outubro, 2011 
${ }^{6}$ A crítica merleau-pontiana ao empirismo está, portanto, vinculada à crítica aos prejuízos clássicos, os quais recusam o saber corporal capaz de orientar a experiência no interior da percepção. Desse modo, segundo Moura, ela “visa exatamente um a priori que reúne, em uma mesma família, tanto o cartesianismo quanto o empirismo, e mesmo a fenomenologia. Pois, na recusa em dar ao sensível uma significação, todos eles se mostrarão velhos cúmplices. $\mathrm{O}$ empirismo será cúmplice do cartesianismo, quando introduz uma «associação» ou uma «projeção das recordações», encarregadas de explicar o surgimento de uma significação pela qual, por si só, o sensível não pode ser responsável. E a fenomenologia será cúmplice de ambos. Pois basta levar a sério que toda redução transcendental é necessariamente eidética, para que a facticidade seja expulsa do território da fenomenologia e para que a constituição - de maneira estranha - termine por dar conta apenas das estruturas essenciais do mundo e perca sua «riqueza concreta»" (MOURA, 2001, p. 243).

$7 \mathrm{Na}$ verdade, não se pode falar em percepção elementar no sentido de uma percepção atomizada, pois a estrutura figura-fundo mostra que qualquer percepção é complexa, já que se trata sempre de destacar uma figura que, concretamente, não pode ser separada de seu entorno ou isolada de seu campo. Como diz Merleau-Ponty: "Quando a Gestalttheorie nos diz que uma figura sobre um fundo é o dado sensível mais simples que nós podemos obter, isto não é um caráter contingente da percepção de fato, que nos deixaria livres, numa análise ideal, para introduzir a noção de impressão. Trata-se da própria definição do fenômeno perceptivo, daquilo sem o que um fenômeno não pode ser chamado de percepção. $\mathrm{O}$ «algo» perceptivo está sempre no meio de outra coisa, ele sempre faz parte de um "campo" (MERLEAUPONTY, 1999, p. 24).

\section{Referências bibliográficas}

BERGSON, H. A Evolução Criadora. Trad. B. Prado Neto. São Paulo:

Martins Fontes, 2005.

DELEUZE, G. Bergsonismo. Trad. Luis B. L. Orlandi. São Paulo: Ed. 34, 1999.

. Différence et Répétition. Paris: PUF, 2003.

FORNAZARI, S, K. O Esplendor do ser: a composição da filosofia da diferença em Gilles Deleuze (1952-68). Tese de Doutorado apresentada ao Dep. De Filosofia da FFLCH/USP, São Paulo: 2005.

LEBRUN, G. "De la superiorité du vivant humain dans L'Évolution créatrice" in Georges Canguilhem. Philosophe, historien des sciences. Actes du Colloque (6-7-8 décembre 1990). Paris: Albin Michel, 1993. 
MACHADO, R. Deleuze, a arte e a filosofia. Rio de Janeiro: Zahar Editor, 2010.

MERLEAU-PONTY, M. Fenomenologia da Percepção. Trad. Carlos A. R. e Moura. São Paulo: Martins Fontes, 1999. La prose du monde. Paris: Gallimard, 2004.

MOURA, C. A. R. Racionalidade e Crise. Estudos de História da Filosofia Moderna e Contemporânea. São Paulo, Discurso, 2004.

PRADO JR, B. Presença e campo transcendental. Consciência e negatividade na filosofia de Bergson. São Paulo: Edusp, 1989.

SILVA, F. L. Bergson: intuição e discurso filosófico. São Paulo: Loyola, 1994. 